\title{
EM TORNO DE O NASCIMENTO DA TRAGÉDIA: TEORIA DO TRÁGICO E INTUIÇÃO ESTÉTICA
}

\author{
André Luiz Bentes ${ }^{1}$ \\ Universidade Federal de Tocantins (UFT) \\ (iD) https://orcid.org/0000-0001-8572-0098 \\ E-mail: andrebentes@gmail.com
}

\section{RESUMO:}

O presente artigo pretende apresentar um recorte da filosofia da arte na Alemanha, nos séculos XVIII e XIX, tendo como foco o contexto em que se insere $O$ nascimento da tragédia, de Nietzsche. Para isso, serão discutidos mais especificamente os conceitos de intuição estética e princípio de individuação, a partir de Schelling e Schopenhauer, respectivamente.

PALVRAS-CHAVE: Intuição estética; Tragédia; Schelling; Schopenhauer; Nietzsche.

\section{AROUND THE BIRTH OF TRAGEDY: THEORY OF TRAGIC AND AESTHETIC INTUITION}

\begin{abstract}
:
The present article intends to present an outline of the philosophy of art in Germany, in the eighteenth and nineteenth centuries, focusing on the context in which Nietzsche's birth of tragedy is inserted. For this, we will discuss more specifically the concepts of aesthetic intuition and the principle of individuation, from Schelling and Schopenhauer, respectively.
\end{abstract}

KEYWORDS: Aesthetic intuition; Tragedy; Schelling; Schopenhauer; Nietzsche.

\footnotetext{
${ }^{1}$ Doutor em Filosofia pela Pontifícia Universidade Católica do Rio de Janeiro ( PUC-RIO), Rio de Janeiro - RJ, Brasil. Professor Substituto de Filosofia da Universidade Federal de Tocantins (UFT), Palmas - TO, Brasil.

BENTES, André Luiz. Em torno de O nascimento da tragédia: teoria do trágico e intuição estética. Griot : Revista de Filosofia, Amargosa - BA, v.18, n.2, p.338-347, dezembro, 2018. 


\section{Introdução}

A partir do final do século XVIII, com a ampliação da reflexão sobre a arte realizada a partir de Goethe e Schiller, abre-se na Alemanha o caminho para a consolidação de uma filosofia que se debruce sobre a tragédia grega, por onde surge uma "tradição de questionamento teórico no cerne da natureza da tragédia" (SILK; STERN, 1981:1), inclusive por meio de uma referência à reformulação do próprio teatro alemão. A tragédia grega é tema de uma ampla reflexão que ocorre na Alemanha: Goethe amplia o ideal de beleza proposto por Winckelmann, à luz da cultura grega, em relação à pintura e à escultura, ao pensá-lo principalmente em relação à poesia e à arte dramática. Com ele, Schiller, profundamente influenciado pela estética kantiana, em sua Teoria da tragédia, percebia o sofrimento do indivíduo exposto pelo drama e voltava-se para a "constituição de uma teoria da arte moderna" (MACHADO, 2006, p. 51).

Em certo momento, concebeu-se que há uma sabedoria inerente à tragédia, "capaz de apresentar a situação do homem no mundo, a essência da condição humana, a dimensão fundamental da existência" (ibidem, pp. 42-43) ${ }^{2}$. Isto significaria uma ruptura com a perspectiva aristotélica, que privilegiaria a poética da tragédia, partindo para a inauguração de uma filosofia do trágico. $\mathrm{O}$ trágico assume aqui o caráter de ideia presente na tragédia, referente à sua relação com o ser de todas as coisas.

Mais tarde, Nietzsche irá pensar a tragédia grega como o resultado de um emparelhamento entre dois impulsos estéticos: o dionisíaco e o apolíneo, uma relação na qual "a luta é incessante e onde intervêm periódicas reconciliações" (NIETZSCHE, 1992, p. 27). Para ele, o surgimento da tragédia grega é oriundo dos cantos religiosos (os ditirambos) promovidos em louvor ao deus da fertilidade, Dionísio. Com isso, o filósofo atribui primazia à música no que se refere à sua concepção de tragédia grega. No entanto, o drama propriamente dito, enquanto obra de arte, necessita de outro elemento artístico para estar completo: a imagem. Este elemento é, para Nietzsche, a contribuição do deus délfico Apolo, caracterizado pela apresentação da individuação como "imagem similiforme de sonho" (ibidem, p. 32).

De um modo geral, o pensamento referente à "totalidade do que existe" é característico do pensamento filosófico moderno a respeito da tragédia ${ }^{3}$. A divisão proposta por Nietzsche revela dois aspectos fundamentais daquilo que ele parece entender por trágico: por um lado, o impulso dionisíaco viabiliza a conexão entre o homem e o Uno-primordial [Ur-einen $]^{4}$ (o que seria o aspecto ontológico da sua concepção), por outro, o impulso apolíneo traz a individualidade através da atualização do Uno-primordial como aparência $[\text { Schein }]^{5}$.

\footnotetext{
2 Segundo Roberto Machado, "nasce com Schelling uma filosofia do trágico" (2006, p. 23) por ter como objeto uma ideia de tragédia.

3 Temos em mente, de modo amplo, o problema da intuição intelectual desde Fichte e seu desdobramento em Schelling e Schopenhauer. Todavia, vale lembrar a importância dessa reflexão para o romantismo alemão como um todo.

${ }^{4}$ Nietzsche originalmente utiliza Ur-einen. Na edição francesa de $O$ Nascimento da Tragédia, P. Lacoue-Labarthe propõe Un originaire [Uno originário]. Ver NIETZSCHE, 1994:31. Optaremos, porém, aqui sempre pela tradução de J. Guinsburg. Neste caso, Uno-primordial.

${ }^{5}$ Este termo alemão nos remete à noção daquilo que parece ser, mas não é, enquanto impressão externa de algo. Caberia também, neste caso, o termo traduzido como ilusão.
}

BENTES, André Luiz. Em torno de O nascimento da tragédia: teoria do trágico e intuição estética. Griot : Revista de Filosofia, Amargosa - BA, v.18, n.2, p.338-347, dezembro, 2018. 
Ainda que consista em uma obra de arte, ao longo de $O$ Nascimento da tragédia Nietzsche se refere constantemente aos que compõem a cena trágica (e isso inclui para ele os espectadores) como entusiastas dionisíacos. Isso nos conduz a reconhecer em tal cena artística a inerência religiosa, como se a tragédia grega compartilhasse, por meio de um só instinto, dois elementos diferentes, pois "o mesmo instinto que produz a arte produz a religião" (MACHADO, 1985, p. 20). Desse modo, temos a impressão de que Nietzsche não distingue os personagens da obra de arte trágica daqueles artistas e espectadores que compõe a cena, por serem todos eles entusiastas dionisíacos.

Perder a individualidade significa, para tal entusiasta, experimentar "ser totalmente um só com o Uno-primordial, com sua dor e contradição" (NIETZSCHE, 1992 , p. 44), sendo o impulso dionisíaco "a chave que lhe abre a vida essencial do mundo" (FINK, 1988, p.17). Esperamos, assim, investigar minimamente este princípio constituinte de tudo que existe e seu meio suficiente de atualização como aparência, a individuação, ao longo de $O$ Nascimento da tragédia. Para isso, primeiramente, buscaremos possíveis encontros entre o pensamento do jovem Nietzsche e os teóricos do trágico que lhe precedem, tendo como fio condutor o conceito de intuição estética.

\section{A teoria do trágico}

Ao considerar os impulsos artísticos que compõem a tragédia grega, para Nietzsche, a oposição entre os mesmos torna-se evidente. Uma contradição insolúvel entre aparência e vida nos é apresentada. Em termos fisiológicos, temos os universos do sonho e da embriaguez; da imagem e da música, em termos estéticos. Este conflito é inerente ao trágico, de Nietzsche.

Segundo Roberto Machado, o antagonismo constituinte das construções conceituais (modernas) sobre o trágico, parece ter uma influência, ainda que paradoxal, da ontologia platônica ${ }^{6}$. A oposição entre verdade e aparência, concebida por Platão, parece ter influenciado os teóricos do trágico a elaborar uma ontologia da tragédia, por meio de uma contraposição valorativa:

Invertendo as conclusões a que chega Platão, esses pensadores foram levados, a partir do século XVIII a encontrar justamente na tragédia as características da oposição ou da alternativa filosófica - metafísica, ontológica - que Platão apresentava à própria tragédia (MACHADO, 2006, p. 46).

Dentre os modernos, a influência de Kant é considerada fundamental para o surgimento do pensamento acerca do trágico. Em sua Dialética transcendental 7, Kant investiga a antinomia da razão pura, a fim de expor os princípios transcendentais de uma cosmologia racional, e "como já indica a expressão de conflito da razão, para a revelar na sua aparência deslumbrante, mas falsa, como uma ideia

\footnotetext{
${ }^{6}$ Ver, a esse respeito, MACHADO, 2006, pp. 44-47. O autor esclarece que considera a influência de Platão paradoxal, pois para este, "um crítico ferrenho do poeta trágico, a tragédia não tem a dignidade de documento ontológico que lhe conferem os modernos".

${ }^{7}$ Parte integrante da Crítica da razão pura, especificamente da segunda divisão da "Lógica transcendental".
}

BENTES, André Luiz. Em torno de O nascimento da tragédia: teoria do trágico e intuição estética. Griot : Revista de Filosofia, Amargosa - BA, v.18, n.2, p.338-347, dezembro, 2018. 
que não se pode conciliar com os fenômenos" (KANT, 2001, p. 380). Assim, sugere-se que "deve-se a Kant a ideia de que a contradição era fundamental, e de que ela poderia significar algo diferente de uma contradição do racional visto pelo entendimento", e a partir daí, para alguns pós-kantianos, "a tragédia foi vista como modelo de uma solução ao que Kant chamou de antinomia" (MACHADO, 2006, p. $48)$.

Em busca da solução para tal antinomia, Schelling concebe um princípio incondicionado, uma unidade última absoluta, onde o saber tenha o seu fundamento. Para isso, é necessária a junção entre a parte e o todo, de modo que não haja separação entre sujeito e objeto. Assim, Schelling conceitua o "eu absoluto":

A filosofia deve necessariamente partir do incondicionado e sua única questão é saber em que consiste esse incondicionado, se ele reside no eu ou no não eu [...]. Para mim, o princípio supremo de toda filosofia é o eu puro e absoluto, isto é, o eu na medida em que ele é simplesmente eu, em que ainda não é condicionado por objetos, mas é posto em liberdade (apud MACHADO, 2006, p. 82) ${ }^{8}$.

Este "eu absoluto" parece expressar uma liberdade absoluta, na medida em que não possui nenhum objeto que lhe oponha. Enquanto um princípio incondicionado sequer pode ser objeto de si mesmo e, logo, também não viabiliza uma consciência de si ${ }^{9}$. Kant, contudo, já se referia ao incondicionado na Crítica da razão pura, todavia, apenas para suprir uma exigência da razão:

\footnotetext{
A razão exigi-o em virtude do seguinte princípio: se é dado o condicionado, é igualmente dada toda a soma das condições e, por conseguinte, também o absolutamente incondicionado, mediante o qual unicamente era possível aquele condicionado (KANT, 2001, p. 381).
}

Eis aqui a diferença de pressuposto para o desenvolvimento do "eu absoluto", de Schelling: para ele, ao contrário de Kant, o saber não pode estar fundado no que é condicionado, e "se o incondicionado é substância, o eu é a única substância" (apud MACHADO, 2006, p. 82) ${ }^{10}$.

Interessa-nos, agora, já introduzir outra concepção utilizada por Schelling: a intuição intelectual. Se Fichte a entendia como a "auto-intuição do eu", "Schelling a refere a todo conhecimento transcendental" (HARTMANN, 1960, 191). Em outro caso, se para Kant a intuição é sempre sensível, por dizer respeito ao meio pelo qual "um conhecimento possa se referir a objetos" (KANT, 2001, p. 61), para Schelling ela pode ser intelectual, na medida em que pode oferecer ao homem um conhecimento do absoluto, em outros termos, "uma intuição produzida pela liberdade, que nos permite ter acesso ao que é" (MACHADO, 2001, p. 86).

\footnotetext{
${ }^{8}$ Trata-se de uma carta de Schelling direcionada a Hegel em 4 de fevereiro de 1795.

9 É inevitável que lembremos aqui do impulso dionisíaco, em Nietzsche, uma vez que este possui dentre as suas características fundamentais o esquecimento de si, gerado pelo rompimento do princípio de individuação. Com isso, é ultrapassada qualquer mediação imposta por algum objeto, para que alguém, sob tal impulso, seja um só com o "Uno-primordial".

10 Trata-se de um trecho retirado dos "primeiros escritos" de Schelling, datados entre 1794 e 1795.
}

BENTES, André Luiz. Em torno de O nascimento da tragédia: teoria do trágico e intuição estética. Griot : Revista de Filosofia, Amargosa - BA, v.18, n.2, p.338-347, dezembro, 2018. 
Em relação à tragédia, Schelling concebe o que lhe há de essencial, em sua Filosofia da arte, justamente pela oposição entre liberdade e necessidade, "entre o eu em sua auto-afirmação e a superpotência objetiva do destino" (ibidem, p. 96):

O essencial da tragédia é, portanto, um conflito real entre a liberdade no sujeito e a necessidade, como necessidade objetiva, o qual conflito não se encerra com uma ou outra sucumbindo, mas com ambas aparecendo em plena indiferença, ao mesmo tempo como vencedoras e vencidas. (SCHELLING, 2001, p. 316).

Dois pontos nos parecem comuns a tudo que até aqui trouxemos. Em primeiro lugar, uma ideia de antinomia, um conflito entre: verdade e aparência; ideia e fenômeno; incondicionado e condicionado; sujeito e objeto; liberdade e necessidade. Em segundo, todas estas antinomias se referem, imediatamente ou não, a relações entre infinito e finito.

Em Schopenhauer, cujo pensamento exerce influência direta no primeiro Nietzsche, a dualidade permanece ao pensar $O$ mundo como vontade e representação. É a partir da relação entre sujeito e objeto, de acordo com as condições de possibilidade da manifestação de um fenômeno, ou seja, com o princípio de razão ${ }^{11}$, que se dá uma representação. Esta se refere sempre às particularidades oriundas da singularidade gerada pelo tempo e o espaço, sendo a manifestação das coisas "somente possível por uma limitação recíproca" (SIMMEL, p. 34). A necessidade de uma dualidade está aqui fundada na concepção schopenhaueriana de que "a realidade imediatamente dada é uma ilusão" (idem). Por isso, o fundamento do mundo não pode estar na relação entre sujeito e objeto e Schopenhauer o encontra na vontade [Wille]. "A vontade é primordial, primária, fundamental" (MACHADO, 2006, p. 168).

Nietzsche, em $O$ Nascimento da tragédia, contrapõe vida e aparência, onde "a vida infinita é ela própria a construtora, a organizadora que fixa formas para seguidamente as destruir" (FINK, 1988, p. 19). Ora, parece haver um fio condutor que permeia tanto esta intelecção antinômica, quanto aquelas a que nos referimos anteriormente, certamente de modo absolutamente diverso. Em Nietzsche, o trágico é inerente ao que existe (individualmente), justamente por este haver se separado da unidade primordial, isto é, por ter se atualizado como aparência, tendendo inevitavelmente ao desaparecimento:

Num mundo trágico não há redenção, entendida como salvação de um existente finito em sua finitude; ali há apenas a lei inexorável do declínio de tudo aquilo que surgiu do fundo do ser na existência individualizada, daquilo que se separou da corrente da vida universal (FINK, 1988, p. 18).

Para Nietzsche, o Uno-primoridal "tende a negar a si mesmo como unidade indiferenciada" (BENCHIMOL, p. 58) ao se manifestar através de individualidades. Também nos parece haver algo comum, segundo a interpretação de Roberto Machado sobre Hegel, quando este último toma como tema principal da tragédia "o divino tal como ele aparece no mundo, através da ação individual" (MACHADO,

11 Ver, a esse respeito, DIAS, 2003, p. 232: "Por princípio de razão ou de causalidade, [Schopenhauer] compreende o fato de todo fenômeno aparecer no espaço-temporal como explicável e efeito de certas causas que dão a razão de ser de um fenômeno".

BENTES, André Luiz. Em torno de O nascimento da tragédia: teoria do trágico e intuição estética. Griot : Revista de Filosofia, Amargosa - BA, v.18, n.2, p.338-347, dezembro, 2018. 
2006, p. 129). O ponto comum aqui, aparentemente, refere-se à manifestação individual de algo absoluto, ou seja, uma contradição inerente a tudo aquilo que existe enquanto parte. E este ponto parece percorrer toda a filosofia do trágico.

\section{A intuição estética}

A intuição para Kant, como vimos, é aquilo que possibilita a um conhecimento relacionar-se com objetos. Contudo, este objeto nos é dado apenas graças à nossa "capacidade de receber representações" (KANT, 2001, p. 61), ou seja, nossa sensibilidade. Isto não faz, porém, com que todas as intuições sejam sensíveis, pois além de terem fenômenos como objeto, as intuições também podem se referir unicamente às formas encontradas a priori no espírito ${ }^{12}$, consistindo em intuições puras, quando se referem ao tempo e ao espaço.

Em um parágrafo integrante de sua Analítica Transcendental ${ }^{13}$, Kant nomeia de apercepção pura a representação que se dá "quando o diverso da intuição possui uma relação necessária ao eu penso" (ibidem, p. 131), isto é, uma unidade estabelecida entre todas as representações da intuição, que ele também chama de "unidade transcendental da autoconsciência, para designar a possibilidade do conhecimento a priori a partir dela" (ibidem, p. 132).

Abre-se, a partir deste ponto, uma discussão pós-kantiana sobre a possibilidade de haver uma intuição que não se restrinja somente à sensibilidade: eis a intuição intelectual ${ }^{14}$. Esta é uma discussão acerca da possibilidade de uma intuição que se relacione diretamente com o entendimento. Segundo Roberto Machado, é "a intuição pela qual o absoluto se determina por si mesmo em sua incondicionalidade, uma intuição de si mesmo na qual o eu se identifica" (MACHADO, 2006, p. 86). Em Schelling, a intuição intelectual é "uma visão translúcida estética do organismo espiritual em seus princípios" (HARTMANN, p. 191), ou seja, a intuição intelectual é aqui viabilizada por meio de uma intuição estética, isto é, ela "só existe na arte" (MACHADO, 2006, p. 90).

Assim, é por meio da obra de arte que se pode ter acesso à "identidade absoluta", pelo seu "poder de apresentar o infinito de modo finito" (ibidem, p. 90). A criação artística corresponde de algum modo ao incondicionado, ao absoluto, ao "espírito criador inconsciente da natureza", assim como "o cosmo não é só um organismo vivente, é também uma obra de arte unitariamente efetuada, a poesia original, inconsciente do espírito" (HARTMANN, 1960, p. 190). Por meio da obra de arte se tem acesso ao que há de inconsciente no sujeito, pela arte ser uma atividade ao mesmo tempo consciente e inconsciente daquele que cria ${ }^{15}$.

Para Schopenhauer, a intuição estética se relaciona diretamente com a ideia de um objeto, isto é, com aquilo que há de geral em uma manifestação singular. Sua característica fundamental é o conseqüente desaparecimento de qualquer vontade

\footnotetext{
${ }^{12}$ Cf. KANT, 2001, p. 62.

13 Trata-se da primeira divisão da Lógica transcendental, esta segunda parte da Doutrina transcendental dos elementos, que compõe a Crítica da razão pura.

14 Nicolai Hartmann a compreende, a partir de Schelling, como "todo fazer consciente das ações ou modos de produção do eu".

15 Para Roberto Machado, em relação à Schelling, "a única diferença entre a criação estética e a natural é que, enquanto a criação natural é um processo inconsciente, a criação genial da arte é ao mesmo tempo, consciente e inconsciente".
}

BENTES, André Luiz. Em torno de O nascimento da tragédia: teoria do trágico e intuição estética. Griot : Revista de Filosofia, Amargosa - BA, v.18, n.2, p.338-347, dezembro, 2018. 
individual, pois "o eu tem que dissolver-se também na imagem, na representação" (SIMMEL, p. 118). Se para Schelling a arte é uma atividade simultaneamente consciente e inconsciente, para Schopenhauer ela é "ao mesmo tempo o efeito e a causa da emancipação do puro intelecto, da vontade" (ibidem, p. 119).

A intuição estética em Schopenhauer, portanto, fomenta a destituição da individualidade. Como isso ocorre? Procuremos, inicialmente, compreender como ele concebe o indivíduo:

Esta pluralidade de indivíduos só é inteligível em virtude do tempo e do espaço; o seu nascimento e a sua desaparição só são inteligíveis pela causalidade; ora, em todas estas formas reconhecemos apenas os diferentes pontos de vista do princípio de razão, que é o último princípio de toda limitação e de toda individuação. (SCHOPENHAUER, 2001, p. 177).

O indivíduo é uma imagem que toma como modelo uma ideia ${ }^{16}$. $\mathrm{O}$ que lhe garante a individualidade é um encontro peculiar entre tempo e espaço, estas duas formas que fomentam a pluralidade, gerando o princípio delimitador das particularidades: o principium individuationis. ${ }^{17}$

A intuição estética, portanto, promove a destituição da singularidade oriunda do tempo e do espaço, no sujeito, o conduzindo a um estado puro de contemplação da ideia, onde "todas as relações, que se referem e poderiam se referir a uma relação mútua com outros indivíduos, desaparecem". Assim, "a intuição estética está fora do tempo em sua essência mais íntima" (SIMMEL, pp. 119-120).

Como se sabe, O Nascimento da tragédia, de Nietzsche, é profundamente influenciado pelo pensamento de Schopenhauer. Por isso, podemos agora buscar o que está em torno da 'intuição estética', descrita implicitamente nesta obra.

Por Nietzsche utilizar, em certos pontos, inclusive as mesmas expressões usadas por Schopenhauer, um olhar desatento poderia cogitar que a intuição estética, em ambos, fosse até mesmo idêntica. Em Nietzsche, por exemplo, a arte também deve promover a destituição da individualidade do artista (o sujeito), em outros termos, a supressão de toda vontade individual:

[...] exigimos em cada gênero e nível da arte, primeiro e acima de tudo, a submissão do subjetivo, a libertação das malhas do "eu" e o emudecimento de toda a apetência e vontade individuais, sim, uma vez que sem objetividade, sem pura contemplação desinteressada, jamais podemos crer na mais ligeira produção verdadeiramente artística. (NIETZSCHE, 1992, p. 43).

Este processo, para Nietzsche, também significa o rompimento do véu do principium individuationis que, aliado ao "terror que se apodera do ser humano [...], na medida em que o princípio da razão, em algumas de suas configurações, parece

${ }^{16}$ Cf. SCHOPENHAUER, 2001, p. 177. O autor evidencia sua influência ao se referir, neste mesmo parágrafo, às ideias de Platão: "Todas estas ideias se manifestam numa infinidade de indivíduos, de existências particulares, para as quais elas são o que o modelo é para a cópia".

${ }^{17}$ Cf. ibidem, pp. 121- 122: “... chamarei ao espaço e ao tempo - segundo uma velha expressão da escolástica, para a qual atraio a atenção, de uma vez por todas - principium individuationis, visto que é por intermédio do espaço e do tempo que aquilo que é um só e semelhante na sua essência e no seu conceito, nos aparece como diferente, como vários, tanto na ordem da coexistência, como na da sucessão".

BENTES, André Luiz. Em torno de O nascimento da tragédia: teoria do trágico e intuição estética. Griot : Revista de Filosofia, Amargosa - BA, v.18, n.2, p.338-347, dezembro, 2018. 
sofrer uma exceção" (ibidem, p. 30), constitui a "essência do dionisíaco". No entanto, ao contrário de Schopenhauer, Nietzsche concebe uma intuição estética que, ainda que não leve em conta a vontade individual, não conduz à dissolução da individualidade: a intuição apolínea, caracterizada pela imagem, enquanto forma delimitada, pela "bela aparência do mundo do sonho" (ibidem, p. 28), pela medida.

Temos, assim, a impressão de haverem duas categorias de intuição estética em Nietzsche. Contudo, para fazer jus à passagem supracitada, somos levados a crer que não podemos pensar em um artista puramente apolíneo, uma vez que esta intuição não promove "a submissão do subjetivo". A solução oferecida por Nietzsche, a partir de uma citação de Schiller ${ }^{18}$, é sugerir que todo artista, antes de conceber sua obra, possuiria um "estado de ânimo musical" (NIETZSCHE, 1992, p. 44), característico de uma intuição dionisíaca, responsável pela ruptura do principium individuationis.

Interessa-nos também investigar outra possível diferença entre o pensamento de Nietzsche e Schopenhauer, referente ao que seria propriamente, para cada um deles, o princípio de individuação.

Conforme já vimos, Schopenhauer utiliza, a partir da escolástica, a expressão principium individuationis para se referir à singularidade oriunda do espaço e do tempo. Seriam estes, portanto, os elementos que constituiriam a individualidade, ou seja, aquilo que se apresenta como aparência, como ele chega a afirmar em $O$ mundo como Vontade e Representação:

[...] perante os nossos olhos, o indivíduo nasce e morre, mas o indivíduo é apenas aparência; se existe, é unicamente aos olhos desse intelecto que tem como única luz o princípio da razão suficiente, o principium individuationis (SCHOPENHAUER, 2001, p. 289).

O indivíduo é aparência da vida, concebida filosoficamente como ideia ${ }^{19}$. E cabe à intuição estética suprimir a Vontade, para que o artista dissolva, através da ideia, a sua própria individualidade. Temos a impressão, aqui, de que a própria aparência, no momento em que pode ser chamada de intuição estética, viabiliza a dissolução da individualidade, que talvez possa ser imaginada como uma ausência de referência espaço-temporal.

Em Nietzsche, contudo, espreitamos uma diferença em relação à sua concepção de individuação. Isso ocorre porque - apesar de também utilizar a expressão principium individuationis, inclusive aludindo também ao espaço e ao tempo - a aparência, para Nietzsche, ainda que seja uma intuição estética (e nesse caso, a apolínea) jamais promove a dissolução da individualidade.

A arte apolínea encontra sua analogia no mundo onírico, o mundo da bela aparência, onde o artista "observa-o precisa e prazerosamente, pois a partir dessas imagens interpreta a vida e com base nessas ocorrências exercita-se para a vida" (NIETZSCHE, 1992, p. 28-29). A vida individual (desperta) encontra no mundo do sonho seu correlato, seja nas cenas agradáveis, seja nas aterradoras, pois nele, assim

\footnotetext{
18 A citação se refere ao processo poético-criativo, relatado por Schiller: "O sentimento se me apresenta no começo sem um objeto claro e determinado; este só se forma mais tarde. Uma certa disposição musical de espírito vem primeiro e somente depois é que se segue em mim a ideia poética" (apud NIETZSCHE, 1992, p. 44).

${ }^{19}$ Cf. SCHOPENAHUER, 2001, p. 289: "... trata-se de considerar a vida filosoficamente, de vê-la na sua ideia".
}

BENTES, André Luiz. Em torno de O nascimento da tragédia: teoria do trágico e intuição estética. Griot : Revista de Filosofia, Amargosa - BA, v.18, n.2, p.338-347, dezembro, 2018. 
como no mundo desperto, "a pessoa vive e sofre com tais cenas" (ibidem, p. 29). Contudo, o mundo onírico não deixa de ser um estado fisiológico que, por meio de sua aparência "reparadora e sanadora", constitui também a vida individual. A questão, que poderia caber aqui, se refere à natureza do mundo do sonho, no sentido de averiguarmos a possibilidade de lhe conceder atributos espaço-temporais, uma vez que se constitui como imagem.

A intuição estética que promove a dissolução da individualidade, em Nietzsche, refere-se à arte dionisíaca, tendo como elementos constituintes a música e a dança, além da embriaguez como estado fisiológico correspondente. Sua característica é a dissolução da individualidade, por meio da supressão de toda aparência. Esta intuição dionisíaca promove a reunião entre o Uno-primordial e aquilo que havia se fragmentado como individualidade, ou seja, como imagem.

Assim, é possível afirmar que existem concepções diferentes de intuição estética, em Schopenhauer e Nietzsche. No que se refere ao princípio de individuação, por sermos conduzidos a pensar que o espaço e o tempo diriam respeito ao mundo do sonho e, que este, parece proteger a individuação por meio de sua ação "reparadora e sanadora", somos conduzidos a conceber que, em Nietzsche, apenas a aparência garantiria, antes de tudo, o aspecto individualizante em uma intuição estética.

\section{Conclusão}

Esperamos ter esclarecido, por hora, alguns pontos referentes ao contexto filosófico em que se insere $\boldsymbol{O}$ nascimento da tragédia.

Em nossa primeira parte, buscamos a mínima compreensão acerca dos problemas filosóficos envolvidos na reflexão sobre o trágico, sobretudo no que diz respeito aos pensadores modernos.

Sob o mesmo fio condutor, em seguida, investigamos a ideia de intuição estética, principalmente a partir de Schelling, sob a influência de Kant. A partir daí, prosseguimos em Schopenhauer até chegarmos à diferença da concepção de intuição estética em Nietzsche. Isso decorre da divisão, proposta por Nietzsche, em dois tipos de intuição estética: a apolínea e a dionisíaca. Enquanto para Schopenhauer a intuição estética promove necessariamente a dissolução da individualidade, para Nietzsche a intuição apolínea promove a individuação.

Finalmente, devido ao nosso interesse sobre a investigação da concepção nietzschiana de princípio de individuação, em $O$ nascimento da tragédia, concluímos nosso estudo comparando tal conceito com aquele que nos é oferecido por Schopenhauer, em $O$ mundo como vontade e representação. Assim, acreditamos haver uma diferença entre tais concepções, por julgarmos que, em Nietzsche, o espaço e o tempo significam, antes de tudo, aparência. Baseamos-nos, por hora, portanto, no pressuposto de que seja a aparência que, para ele, conduza a tal princípio. Por pensarmos aparência sempre em relação a um sujeito, enquanto imagem, sugerimos que o princípio de individuação, em $O$ nascimento da tragédia, seja considerado como aparência, isto é, o princípio de atualização da imagem.

BENTES, André Luiz. Em torno de O nascimento da tragédia: teoria do trágico e intuição estética. Griot : Revista 


\section{Referências}

BENCHIMOL, M. Apolo e Dionísio - arte, filosofia e crítica da cultura no primeiro Nietzsche. São Paulo: Annablume, 2003.

DIAS, R. Nietzsche e Schopenhauer: uma primeira ruptura. In: A fidelidade à terra Arte, natureza e política: Assim falou Nietzsche IV, Rio de Janeiro: DP\&A Editora, 2003, pp. 231-243.

FINK, E. A filosofia de Nietzsche. Tradução: Joaquim Lourenço, Lisboa: Presença, 1988.

HARTMANN, N. La filosofia del idealismo aleman. Tradução de Hernán Zucchi. Buenos Aires: Sudamericana, 1960.

KANT, I. Crítica da razão pura. Tradução de Manuela P. dos Santos e Alexandre F. Morujão. Lisboa: Fundação Calouste Gulbenkian, 2001.

MACHADO, R. Nietzsche e a verdade. Rio de Janeiro: Rocco, 1985. O nascimento do trágico: de Schiller a Nietzsche. Rio de Janeiro:

Jorge Zahar Ed., 2006.

NIETZSCHE, F. O nascimento da tragédia. Tradução de J. Guinsburg. São Paulo: Companhia das Letras, 1992.

SCHELliNG, F.W.J. Filosofia da arte. Tradução de Márcio Suzuki. São paulo: Edusp, 2001.

SCHOPENHAUER, A. O mundo como vontade e representação. Tradução de M. F. Sá Correia, Rio de Janeiro: Contraponto, 1985.

SILK, M. S.; STERN, J. P. Nietzsche on tragedy. Londres: Cambridge, 1981.

SIMMEL, G. Schopenhauer y Nietzsche. Tradução de José R. Pérez Bances. Madrid: Francisco Beltran, 1915.

Autor(a) para correspondência: André Luiz Bentes, Universidade Federal de Tocantins, Avenida NS 15, Quadra 109 Norte, Plano Diretor Norte, CEP 77001-090, Palmas - TO, Brasil. andrebentes@gmail.com 